\title{
A QUESTÃO CULTURAL E O ENSINO DE LIINGUAS
}

Your culture did not say to you " Hey, this is one way of looking at things in the world". Rather, we are told, "This is the way of looking at the things. This is the tuth."

Bennett, 1996:15

\section{Márcia Rosseti (UFAL)}

Sabemos que a vida atual demanda um grau de complexidade cada vez maior na aquisição de conhecimentos e de habilidades para lidar com as exigências da tecnologia e das relações sociais. O contexto educacional precisa promover mudanças consideráveis para atender a essas necessidades. Não se trata apenas de atulhar as escolas com aparatos tecnológicos de última geração - embora a utilidade e a necessidade de muitos deles seja inegável -, mas muito mais de atualizar o processo educativo, a instrução. É fundamental que a instituição de ensino possa efetivamente ajudar o aluno a se tornar uma pessoa apta para enfrentar os desafios de viver no século XXI.

O mundo atual está lidando com uma crescente abertura de fronteiras propiciada pela maior facilidade de mobilização (turismo e migração), de comunicação e de acesso à informação. Já não é possível, nos dias de hoje, manter as influências externas controladas pelos costumes, pelos valores nacionais ou pelas diferenças entre as línguas. A economia de mercado domina as relações entre as nações e o consumismo atravessa todas as relações humanas. Os países desenvolvidos, liderados pelos Estados Unidos, dominam o mercado mundial e ditam suas leis, tornando os países pobres dependentes de imposições externas para se desenvolverem. Mas a lógica do lucro e do poder aprofunda as desigualdades trans e intranacionais, impede a autonomia necessária para a busca de soluções para problemas nacionais, reduz os cidadãos a meros consumidores e admiradores incondicionais dos valores e da cultura das nações ricas e, ainda, apresenta o capitalismo como única forma de interação social passivel de ser bem sucedida.(vide Santos, 1995:20, 22,58,90). 
Tourraine (1996) analisa duas tendências opostas que fazem face a esse contexto: um universalismo que se traduz na massificação, na aceitação completa da ideologia dominante, e um localismo obsessivo que se volta inteiramente para uma identidade nacional, uma etnia ou uma religião. Em ambos os extremos, não há lugar para a diversidade das culturas e das experiências, para a afirmação da própria particularidade e para o reconhecimento do outro. A saida pode estar na educação de jovens capazes de lutar por uma organização social que respeite, a um só tempo, os direitos fundamentais dos seres humanos baseados em principios universais de dignidade humana e de direito à diversidade. O ser humano do século XXI não pode prescindir da subjetividade - da liberdade, da criatividade, da autonomia - nem da cidadania que se define, principalmente através de direitos.

Para a construção dessa "igualdade sem mesmidade" (Santos, 1995:278) faz-se necessário trazer o exercício da política - que se encontra setorizada - para a prática social, de modo a facultar seu exercício a todos os cidadãos e não somente a um setor especializado da sociedade. Santos (id.ib.:271) define politizar como "identificar relações de poder e imaginar formas práticas de as transformar em relações de autoridade partilhada". Essa repolitização das práticas sociais permitirá maior consciência das formas de opressão e dominação e possibilitará encontrar caminhos para o "exercício de novas formas de democracia e cidadania" (op. cit.:271).

O processo educativo também deve ser politizado, para que possa efetivamente arcar com a responsabilidade de ajudar a formar sujeitos e cidadãos capazes de produzir sentidos no mundo e capazes de transformar as relações sociais com consciência, evitando tanto a massificação quanto o sectarismo e a segregação. Tourraine (1996) afirma que é tarefa fundamental da educação

desmassificar a sociedade pela multiplicação dos espaços e processos de decisão que permitem estabelecer a aproximação entre as exigências impesssoais que pesam sobre a ação e os projetos e preferências individuais. (op.cit.:199) [...] a educação, no plano de programas deve comportar três grandes objetivos: o exercicio do pensamento cientifico, a expressäo pessoal e o reconhecimento do outro, isto é, a abertura a culturas e sociedades afastadas da nossa no tempo e no espaço[...] (op.cit.:200). 
Nos tempos modernos, educar é oferecer condições para maior consciência possivel acerca das questões mundiais, nacionais e locais, e da inter-relação entre elas. Basicamente, a realidade é significada pela linguagem que constitui a consciência, o ato teleológico e todas as relações entre os seres humanos. Sendo assim, torna-se extremamente importante para a educação o espaço do ensino de línguas que deve focalizar questões como a função e o papel da linguagem e colocar em prática ações que levarão o estudante a usar efetivamente a língua e a entender profundamente suas manifestações, adquirindo, assim, o conhecimento lingüístico adequado para que possa assumir a responsabilidade pela defesa de seus direitos de cidadão e de sua vida pessoal.

Como bem o diz Orlandi (1996),

[...] dado o silenciamento do politico, por que è na lingua que se explicitam as confrontações? Porque a lingua pertence a todos e é, ao mesmo tempo, o que temos de mais propriamente nosso. Lugar de relação à história e ao social e lugar de singularidade. (op.cit.:131)

Sendo assim, quanto mais clara ficar a posição das línguas enquanto constitutivas, juntamente com o histórico, o social e o ideológico, dos modos de produzir sentido no mundo, mais politizados e conscientes serão os sujeitos enquanto cidadãos e enquanto indivíduos emancipados. Isso pode significar visualizar-se como parte de uma formação discursiva (lugar de um determinado grupo nas relações sociais que vai determinar "o que pode e deve ser dito" (Pêcheux) que remete a uma formação ideológica que, por sua vez, determina as formas de relação social entre os grupos e os valores que nelas se inscrevem.

Expõem-se assim os diversos dialetos e registros falados em uma sociedade, os modos como eles delimitam os lugares na escala de valor da sociedade e a imposição de uma língua "pura" e "correta" como representativa dos cidadãos de uma nação. No âmbito universal, a mundialização de valores e ideais nos vários níveis (jurídico, social, econômico etc.) também se impõe, a partir do ponto de vista das relações existentes na sociedade do país economicamente mais forte e, por isso também, faz-se urgente conhecer essas relações para que se possa conquistar a igualdade de condições bem como manter o espaço das diferenças entre as culturas. 
Diante da situação do mundo contemporâneo, é, sem dúvida, imprescindível para a vida atual que, além do estudo da língua nacional, seja aprendida uma língua falada internacionalmente, seja pelos motivos mais óbvios advindos do encurtamento das distâncias a comunicação entre pessoas de países diferentes, o uso de aparatos tecnológicos, tais como o fac-símile, correio eletrônico, os negócios com outros países, a necessidade de atualização profissional etc. -, seja por outras razões igualmente importantes: dar acesso ao conhecimento de outros modos de vida, cultura e expressão que ampliam e/ou desenvolvem uma compreensão mais profunda dos valores e da identidade cultural dos aprendizes assim como da linguagem que ele usa para interagir no complexo da vida social. $O$ primeiro objetivo é puramente instrumental, oferecendo aos alunos conhecimentos práticos para dar amplitude a sua atuação na vida moderna, enquanto que o segundo vai dar a dimensão desse saber para que não haja o risco de que, sob a aparente neutralidade do saber téenico, no qual só o aspecto lingüístico-formal é claramente trabalhado, estejam sendo introduzidas inevitavelmente a cultura e a ideologia das sociedades que usam essa língua.

A idéia é saber exatamente para que fins práticos uma língua estrangeira é estudada, mas, ao mesmo tempo, também reconhecer como inerentes aos discursos das línguas suas condições de produção, seus bens culturais e a história do povo que interage nessas línguas. Evitar colocar esses elementos, às claras, é escamoteá-los, arriscando que sua passagem despercebida ocasione sua incorporação involuntária.

O cerne da questão está na ação pedagógica que venha a contemplar uma autêntica atuação do aprendiz, garantindo o espaço de sua voz, um professor facilitador e participante do processo dentro de um paradigma que sustente conceitos de linguagem que a coloquem na prática da interlocução, sempre em relação constitutiva com a história, as formações discursivas e a ideologia. Desse modo, pois, o estudo das línguas se orienta em direção ao funcionamento da linguagem produzida no mundo - o discurso - onde as palavras são menos itens de sistemas de formas normativas - sinais - e mais signos cujos sentidos são constituídos pela interação nos diferentes contextos de sua produção. 
Os professores de língua estrangeira estão acostumados a observar na sua sala de aula os passos de um processo, que torna os aprendizes autoconscientes no conflito de acomodar um novo modo de dizer e ver as coisas do mundo, no espaço fechado de seu monolingüismo. É bastante comum considerar as interações verbais como pessoais e independentes, e as escolhas lingüísticas como manifestações naturais e neutras "dadas por si mesmas e universalmente válidas” (Zimas, 1983: 87).

No estudo da LE abre-se mais facilmente a possibilidade de ver sentidos "evidentes" sob outro ponto de vista. Por exemplo, o sentido da palavra "democracia" pode variar dependendo de quem a pronuncia, se, digamos, um político de extrema-direita, um socialista ou uma mãe tentando contornar uma rusga familiar. É lidando com descobertas desse tipo que o aprendiz pode se tornar consciente do funcionamento lingüístico e vai se abrindo para novas experiências, pois na impossibilidade de reduzir o novo ao conhecido, i.e., de tratar a LE como algo - ¿l decifrado à luz de sua própria língua, começa a vê-la como um ....esso vivo e dinâmico cujas diferenças em relação à LM colocam em evidência a natureza de sua constituição e os vários papéis que os interlocutores assumem quando nela inscritos. Essa descoberta vai desde a apreensão de diferentes maneiras de atuação na materialidade lingüística até as atitudes em relação ao semânticopragmático e cultural das línguas.

Sendo a língua uma prática social e a cultura parte integrante da língua, temos que considerar ir além do reconhecimento lingüístico e metalingüístico, adentrando na consciência cultural que remete ao entendimento e ao respeito pela diferença. Segundo Kramsch (1994), a cultura não é informação transmitida pela lingua, mas sim uma característica da língua. Uma proposta educacional deve atender a uma pedagogia dialógica que destaca o papel das muitas vozes que perpassam o discurso no contexto e no texto.

Principalmente devido à tecnologia e aos interesses econômicos, o mundo parece menor e as relações entre os países cada vez mais próximas. Se, por um lado, o isolamento não é desejável nem possível, por outro, a ameaça de ser absorvido pela cultura do outro é um problema a ser encarado. A instituição escolar é um ótimo lugar de discussão acerca dessas questões, em especial no ensino de línguas já que estas são instâncias mais importantes da presença da cultura 
não somente como materializações concretas de seus elementos como as manifestações intelectuais ou os costumes, as crenças e os conhecimentos acumulados -, mas principalmente como conjunto de práticas social e historicamente produzidas que servem de "marco objetivo de referência" (Perus,1984:31) para as ações humanas, bem como para o modo de entender as relações entre os seres e a realidade.
A(s) ideologia(s), para essa autora,
não é (não são) um simples componente da cultura entre muitos outros. Enquanto elaboração sistemática das experiências, necessidades e aspirações das distintas classes sociais [as ideologias] não habitam simplesmente a cultura, mas intervêm ativamente na seleção, hierarquização e estruturação de seus componentes. ${ }^{1}$

Esse conceito de cultura e sua articulação à ideologia vão nos permitir apontar a questão da presença dessas determinações nos discursos de forma mais abrangente, apontando para o fato de que os grupos sociais organizam os elementos culturais de forma diversificada, devido à ideologia. As culturas nacionais são, em geral, mais uma imposição dos interesses dos que controlam os "meios de produção e difusão cultural" (op.cit.:32) do que manifestações autênticas dos anseios e das tradições dos grupos sociais representativos das nações, e o ensino de línguas traduz essa situação, pois valoriza e difunde apenas a concepção de cultura e de língua das classes dominantes nacionais e internacionais. É possivel mudar esse quadro? Talvez sim, se optarmos por uma abordagem dialógica na sala de aula onde haja lugar para expor, elaborar e discutir os conteúdos didáticos, levando em consideração as dimensões dos discursos (lingüísticas, intertextuais, ideológicas e discursivas) e suas condições de produção.

A abordagem de ensino que trabalha a relação cultura/linguagem não pode ser confundida com prestar informações sobre costumes, literatura ou estereótipos nem consiste em assimilar a identidade cultural de outros povos, menos ainda integrar diferenças

no es (no son) un simples componente de la cultura entre otros muchos más. En cuanto elaboración sistemática de las experiencias, necessidades y aspiraciones de las distintas clases sociales no habitam simplesmente en la cultura, sino que intervienen activamente en la selección, jierarquización y estruturación de sus componentes. 
com vistas a uma cultura globalizante. A proposta é aprender a compreender e respeitar as diferenças, é distanciar-nos de um etnocentrismo que nos força a ver a nossa realidade e a dos outros centrados em uma visão unívoca da nossa cultura, considerada como verdadeira. Esse distanciamento não se coloca em extremos: o de negar nossa origem e absorver os valores do outro e o do sentimento xenófobo que despreza tudo que não é nativo. Podemos sim romper com a nossa lógica habitual para dialogar com a outra língua sobre os diversos pontos de convergência e de divergência entre elas, conscientizando-nos em relação ao outro e a nós mesmos.

Kramsch (1994) pretende que coloquemos o aluno na fronteira entre as linguas e culturas, de modo que, olhando para os dois lados, cle possa livrar-se da percepção monolítica e avançar para potenciais mudanças no que concerne a valores e atitudes sociais bem como em relação à apropriação do potencial expressivo de sua língua. Esse domínio é promovido pelos virtuais conflitos entre as línguas, que irão ampliar a experiência do aluno com as línguas e seus usos.

Bennnett (1996) chama a atenção para o conceito de aldeia global preconizado por McLuhan. É certo que os satélites, o facsimile, o correio eletrônico, a Internet e outros recursos tecnológicos permitem rápida e fácil comunicação (embora pouco acessivel aos paises pobres), não importando a distância, mas isso não significa aceitar a idéia de que as culturas estão se misturando, dissolvendo-se em um só caldeirão. Idéias desse tipo invariavelmente contêm uma imposição cultural disfarçada em propostas de entendimento e união: enfatiza-se um padrão intelectual considerado detentor de melhores valores e exclui-se um outro ao qual se atribui ignorância ou irracionalidade. É o que acontece, por exemplo, com as minorias, com os indios e negros, e com os países subdesenvolvidos. Faz-se uma campanha de não-discriminação, de tratamento justo e igual a todos os cidadãos, justificando, assim, a urgência em providenciar meios que introduzam esses cidadãos na "verdadeira" herança cultural da humanidade e nos seus "legítimos" valores. Entretanto, no extremo oposto dessa concepção de aceitação está a total negação das outras culturas. Nesse caso, um etnocentrismo exacerbado impede as pessoas de olhar o diferente como um dos modos de se ver as coisas. Acreditamos ser esse o caso, por exemplo, do repúdio violento dos fundamentalistas islâmicos aos turistas que visitam seus países, um posicionamento radical visando preservar a univocidade de uma 
estrutura social autoritária que esmaga qualquer posicionamento contrário. Em última análise, os extremos se equivalem.

Sempre vemos o mundo a partir do ponto de vista da nossa cultura. As línguas e os costumes dos outros se colocam como peculiares ou bizarros, pois é no nosso próprio modo de pensar e agir que está a incontestável "verdade". Por isso não basta observar o diferente e o interessante, devemos sim descobrir que nós também somos diferentes na perspectiva do outro. Esse é o modo de se encarar o constante intercâmbio cultural promovido pelo encurtamento das distâncias.

Essa atitude perante a diversidade não vem automaticamente embutida na aprendizagem de uma LE. Acreditamos que. no ambiente escolar, somente uma pedagogia crítica contribui para o desenvolvimento do autoconhecimento e da apreciação da diversidade. Um exemplo típico de ponto de vista etnocêntrico é o caso citado por Bennett (op.cit.) a respeito de um grupo de turistas que, perguntados sobre Tóquio, respondem: " $E$ lama cidade grande quanto outra qualquer, com muitos carros, muitos edificios e McDonald's". Esses turistas estão atinando para aquilo que sua visão de mundo thes permite observar, pois estar presente a eventos não corresponde automaticamente a experimentá-los. George Kelley (apud Bennett, 1996) diz que a experiência é o modo como construímos esses eventos, e "quanto mais modos de construir ou interpretar. eventos nós possuimos mais ricas serão nossas experiencias" (op. cit.:15). Um americano, portanto, não tem que deixar de gostar do hamburguer do McDonald's para, digamos, saborear um sashimi, não há porque misturar os dois, não reconhecer ou rejeitar um em favor do
outro.

Um dos meios de desenvolver mudanças em concepções unilaterais na maneira de entender as coisas é a interferência, é oportunizar intencionalmente a construção de outros modos de conceber eventos e idéias. Vale enfatizar que o papel do professor não é o de mudar posições, mas é definitivamente o de repensar elementos para mudar perspectivas.

And the more ways we have of construing or interpreting events, the richer will be our experience 
Portanto, o que pretendemos é reconhecer as similaridades e as diferenças? Sim. É oportunizar empatias culturais? Também. Mas sobretudo é compreender que nosso posicionamento individual e nossa organização social constituem um dos modos de se conceber o universo, de tal forma que, refletindo sobre essas diferenças, poderemos gerar nossa própria identidade com base na escolha dentre as variadas opções. É compreendendo que no processo de interação humana nossa enunciação ecoa as vozes (Bakhtin, 1991) da formação social e ideológica na qual nos inserimos e que nas outras culturas estrangeiras ou regionais - formas diferentes de diálogo, cujas vozes variam em grau de similitude e diferença em relação à nossa, nos desafiam a procurar-lhes oṣ sentidos e as intenções. Esse entendimento abrange não somente culturas estrangeiras, mas também as variadas formas de dialetos, expressão artística, costumes e crenças existentes nas comunidades e nas diferentes classes sociais.

A questão é que, sem instrução sistemática o aluno dificilmente se apercebe da natureza relativa do sentido ou relaciona esse sentido ao contexto sócio-histórico e à cultura como um dos seus construtos. Sabemos que nosso sistema educacional valoriza sobremaneira o conhecimento informacional, a colagem de idéias, a definição precisa de uma única voz, desfavorecendo o conhecimento crítico, advindo das possibilidades interpretativas do material didático apresentado. No contexto geral, nem o aluno nem o professor têm consciência de suas ligações com uma cultura específica ou podem apontar, de maneira sistemática, seu modo de se representar para eles em termos de atitudes, formas lingüísticas e de lógica explicativa.

Kramsch (1994) acredita que o diálogo entre duas línguas ajuda a quebrar a barreira dos significados prontos, confronta sentidos dados como certos, provoca rupturas nos padrões de raciocínio de LM e na articulação do novo com o antigo, faz aflorar um modo particular de ver uma cultura à luz de outra. A compreensão e a apreciação pelas diferenças culturais entre as nações tornam-se mais fáceis pelo fato de que não estamos filiados à cultura estrangeira, e o distanciamento permite mais objetividade à análise. Essa experiência com a diferença cria um novo lugar, de onde podemos analisar nossa sociedade, as culturas que nos cercam e a superestrutura ideológica que as abrigam.

$\mathrm{Na}$ prática, a conscientização intercultural se traduz nas seguintes ações: (a) buscar no discurso o eco de nossa organização 
social; (b) tentar determinar as intenções implícitas nas escolhas lingüísticas; (c) distinguir o valor referencial e o valor sóciopragmático das expressões; e (d) reconhecer valores diferentes, comparando e contrastando expressões, tais como metáforas e clichês.

Em uma sociedade monolíngüe, a experiência e os conhecimentos são veiculados pela lingua materna e são formados e delimitados pela identidade cultural daqueles que dela fazem parte. Bakhtin (1990) diz que "vemos 'a cidade e o mundo' através do prisma do meio social concreto que nos engloba" (op.cit.:112). A atividade mental das pessoas é modelada pelas condições descritas por esse autor, mas embora ela não seja homogênea. pois depende do grau de orientação social dos individuos, a apreensão das relações intra e extralingüísticas é delimitada pela experiência vivida dentro do contexto histórico-social de uma dada comunidade.

Un episódio que poderá ilustrar esse fato ocorreu nos Estados Unidos durante uma entrevista que fazíamos acerca das diferenças entre as línguas. Pedíamos aos entrevistados que lessem um texto de uma revista trazida de seu país e fossem discorrendo acerca das idéias que thes ocorressem a partir do texto, do conteúdo e da lingua propriamente dita. Uma jovem kwatiana (E.), estudando em uma universidade americana já há vários meses, discorria orgulhosamente sobre a antiguidade e riqueza da lingua árabe - sua LM - comparada à limitada capacidade expressiva da lingua inglesa (sic). Pedimos-lhe que nos esclarecesse melhor com exemplos e ela, entào, apresentou algumas metáforas elaboradas, que em inglês seriam ditas de modo direto e econômico e que comprovariam que o árabe usa mais a imaginação (sic) e, em seguida, mostrou-nos una lista de palavras verbos, substantivos e adjetivos - usadas exclusivamente por mulheres, enquanto que a lingua inglesa trazia, para ela, essa limitação de vocábulos que, às vezes, dificultava a vida das mulheres árabes nos Estados Unidos. Conversamos também sobre o ensino de Lingua Inglesa em seu pais e ela nos informou que geralmente se estuda essa língua para falar com empregados indianos e para ter acesso à ciência. Textos literários ou de revistas, por exemplo, nunca foram usados na aprendizagem durante seus estudos. Ela pessoalmente leu Charles Dickens, mas achou monótono.

O ponto de vista de E. deixa claro que seu modo de ver as diferenças entre culturas é o que Bennett (1996) chama de 
"experiencia énocentrica na vizinhança da diferença" (op.cit.:15). Lla só vê aquilo que está preparada para ver e pode continuar assim, a nào ser que algo "intervenha e oportunize um modo diferente de construir eventos" (op.cit.:15). Além disso, ao que parece, pelo menos no caso das mulheres, o ensino da LE procura apagar marcas culturais indescjaveis.

Duas conclusões podem ser tiradas da fala da jovem árabe: (1) a lingua materna produzida dentro de um contexto social especifico delimita um modo próprio de se pensar e ver as coisas e o mundo: (2) conhecer outra lingua, verdadeiramente, implica ser capaz de reconhecer diferentes maneiras de organizar a realidade de tal modo que nos ofereça também a possibilidade de ver como a nossa identidade vem sendo construída.

Nosso pedido a E. para que opinasse sobre a razão da endencia cada vez maior da lingua inglesa de, ao invés de procurar acentuar as divisões sexistas presentes na lingua (por exemplo Ms. no lugar de Mis. e chairperson para chairmun). estar tentando neutralizálas. fê-la cair em um silencio reflexivo.

Porém, ensinar linguas estrangeiras implica assumir um posicionamento absolutamente essencial: a interferência da instrução do protessor através de textos. discussòes em grupo e outras atwidades interativas e colaborativas - não pode assumir posições dicotomicas entre certo/errado ou verdadeiro/falso. pois a idéia é promover a reflexão crítica c analitica para que se possa pensar as dilerenças históricas, filosóficas, culturais e lingüísticas entre as comunidades. As transformações que poderão vir a acontecer devem ser fruto de uma autoavaliação promovida pela variedade, sem que isso constitua qualquer tipo de imposição para absorção das idéias dos outros.

O consenso social. contido em muitos discursos politicodemocráticos, procura a atenuação do conflito; é um modo de valorizar apenas uma "verdade" e de colocar todos cujas atitudes sejam divergentes dicotomicamente do outro lado, i.e., da discórdia e da mentira. Documentos oficiais. livros didáticos e programas de ensino comprovam que as variaçoes cultural e lingüística não são 
reconhecidas institucionalmente, já que aparecem como "obstáculos à igualdade proclamada dos cidadãos [... $]^{3}$ (Jucquois, 1994:55)

A diversidade cultural à qual a pedagogia de língua materna atribui valor está diretamente relacionada à literatura e à língua-padrão falada pela classe economicamente privilegiada, quer dizer, são os gêneros literários e o estilo canônico que delimitam essa noção. Podese observar isso nos livros didáticos e nas práticas de sala de aula, mas tomemos como exemplo aquilo que podemos chamar de o resumo do paradigma vigente: os programas oficiais que, até a implantação dos programas recentemente elaborados, ainda são utilizados. O programa de literatura proposto pela Secretaria de Educação do Estado de Alagoas (1982) apresenta o significado da disciplina Literatura Brasileira "[...] como expressão artística da alma de nossa gente,[...] a reflexão do itinerário histórico percorrido pelo nosso povo" (op. cit.:15). Seu objetivo está ligado à idéia de que a produção literária nacional espelha a construção da nacionalidade e a cultura nacional. A noção de cultura do nosso povo, portanto, tem como referência somente o texto literário canônico e nele faz seu parâmetro de valor, e a diversidade restringe-se aos gêneros literários.

O programa de Língua Portuguesa enfatiza o fato de que "dessa força interior [do homem] nasce a necessidade irrefreável de comunicação com o mundo exterior" (op. cit:11) e apresenta como objetivo no domínio afetivo o desenvolvimento do "gosto pela língua, descobrindo-lhe os valores de expressivos elementos da cultura nacional"(op. cit.:11). As unidades de ensino discriminadas nessa proposta curricular destacam tipos textuais (descrição, narrativa, correspondência comercial, relatos etc.) e gramática formal; contudo, não fazem mais nenhuma referência à cultura.

Dois valores estão presentes nesse discurso: a lingua como algo abstrato, como capacidade exclusivamente subjetiva (força interior) e a cultura (expressão artística) como elemento contido em determinados modelos a serem descobertos e possivelmente imitados. A língua oficial, o padrão usado pela classe que detém o poder, é ensinado em nome de uma homogeneização social, buscando uma integração pela atenuação ou apagamento da diferença (Jucquois, 1994). Nessa linha de raciocínio, Jucquois mostra que na pedagogia de

obstacle a l'égalité proclamée des citoyens[...]. 
lingua materna a diversidade é considerada como elemento de desunião e de discriminação: todos são iguais perante a lei, então a gramática também existe para todos e, assim como a lei, não pode ser ignorada. Desse modo, em nome da igualdade prevista na lei só pode haver um estilo lingüistico conservado pelas gramáticas, pelos dicionários, pelas obras literárias etc. Esse autor prossegue dizendo yUC o

consensualismo que o Estado Moderno constantemente afirma ou exige, repousa sobre uma pedagogia de obediência e de submissão, reveste-se de racionalidade e de progresso para calar as vozes discordantes, afirma os valores libertários da espontaneidade do qual entrava, por todos os meios, o exercicio ${ }^{4}$ (op.cit. : 32 ).

Resumidamente, pode-se dizer que os textos trabalhados nas aulas de lingua portuguesa servem para mostrar ao aluno os modos de "bem expressar" e para "enriquecer seu vocabulário". O primeiro é praticado nas cópias de respostas prontas retiradas do texto referência do "bem expressar", e o segundo está contido em palavras de dominio quase que exclusivamente da linguagem escrita. Já o enriquecimento de vocabulário se dá a partir de glossários ou reprodução de palavras do texto em frases para a memorização. Os discursos se impõem por si mesmos e a pedagogia nào tem lugar de diálogo.

Em se tratando dos programas de língua estrangeira, há sempre uma previsão de que novas realidades culturais serão desveladas para o aluno. Por exemplo, o programa oficial acima mencionado (1982), na parte referente à lingua estrangeira - inglês, em um dos seus objetivos, espera ensinar o aluno "a respeitar e valorizar a cultura e a civilização dos povos de língua estrangeira além de desenvolver o processo de comunicação pela ampliação de um novo código lingüístico, reforçando a capacidade de compreensão" (id. ib.. $1982: 21$ ). Entretanto, para cumprir essas metas, as unidades de ensino são compostas de uma lista de itens gramaticais que deverão ser aprendidos e, no terceiro ano, sugere o estudo intensivo de textos informativos concomitantemente a revisões gramaticais. Durante

Le consensualisme qu'affirme ou qu'exige constamment l'Etat moderne repose sur une pédagogie de l'obéissance et de la soumission, il s'habille des vêtements de la racionalité et du progrès pour taire les voix discordantes, il affirme les valeurs libertaires de la spontanéité dont il entrave, par tous les moyens, l'exercice. 
quatro anos do primeiro grau e mais três do segundo grau, na maioria das escolas alagoanas, o aluno tem como disciplina a língua inglesa, vista como código a ser aprendido através de exaustivos exercícios de memorização de vocabulário e de gramática estrutural, e a cultura destacada do contexto lingüístico vem sob a forma de curiosidades sobre o país onde a língua é falada. Una monumental perda de tempo e energia, mas que segue o paradigma de conhecimento passivo, superficialmente analisado (análise da estrutura lingüística superficial), que também é usado no ensino de português: o professor informa, o aluno repete e decora.

Nesse contexto que Orlandi (1987) chama de circular por só oportunizar a reprodução e a cópia, mas não mudanças, dificilmente aparece o lugar da reflexão critica que venha a proporcionar espaço para formação de cidadãos cujo controle verbal permita compreender e produzir discursos que cada um deles, como sujeito, constituindo a interação, sabe ser único e coletivo, individuo e ser social. A heterogeneidade lingüística, cultural e social reconhecida institucionalmente e prevista na pedagogia das línguas. abre espaço para o dialógico; caso contrário, prevalece uma padronização condicionada por valores do grupo economicamente mais forte.

É através da língua que circulam valores, modos de raciocínio e ideologias, e é nela que as formas do discurso de um determinado grupo social tornam-se prescritivas e hierarquicamente superiores, desvalorizando, diminuindo ou desprezando as outras. Estudar as línguas é aprender a se comunicar, mas é também saber que elas são, caracteristicamente, o lugar principal da presença do ideológico, tanto daqueles ideais que constituem o modo de interagir de grupos majoritários quanto daqueles advindos da manipulação que articula a preponderância da ideologia da classe que está no poder. Preparam-se, assim, os estudantes para suas futuras atuações nas várias esferas da sociedade. Sem essa consciência, instalam-se, con facilidade, a manipulação e a dominação.

A aprendizagem de uma LE é o próprio encontro com a diversidade $\mathrm{e}$, por isso, tem condições de dar uma significativa contribuição na tomada de consciência crítica, no uso e na interpretação de discursos.

Um ponto importante a ser observado é que o conceito de consciência crítica de que falamos fundamenta-se em Bakhtin (1990). 
Consciência não é somente uma manifestaçào do psiquismo (do espirito), mas sim um grau de clareza e de acabamento formal da atividade mental, diretamente proporcional a um grau mais elevado de orientação social. Bakhtin (1990) afirma a existência sócio-ideológica da consciência referindo-se ao fato de que a estrutura da atividade mental é tão social quanto sua objetivação interior (:114). Baseamos nossa concepção acerca dos diferentes niveis de consciência também nesse autor, quando ele destaca que $O$ gran de consiciencia, de clareza, de acabamento da atividade mental é diretamente proporcional ao séu grau de orientação social "(:114).

Distinguimos, portanto, quatro linhas mestras na nossa perspectiva de consciencia: (a) tem origem social: (b) tem a linguagem como material semiótico; (c) é atividade orgànica e dinâmica: (d) apresenta-se em maior ou menor graus. Essa concepção de consciência se traduz numa pratica que busca a conscientização dos modos de operar de seu médium - a linguagem através de um processo dialógico que proporciona a obtenção de um grau mais elevado de consciência, promovendo. assim, um conhecimento crítico e transformador.

Bakhtin (1990) se preocupa com o papel histórico da palavra estrangeira na veiculação da ideologia do dominador ou colonizador. A estrutura sócio-politica de um país "conquistado" seria organizada pela palavra estrangeira, que invade a consciencia ideológica do dominado e impoe sua cultura. sua civilização e seus modos de pensar. que passam a ser considerados como ideais. A história do imperialismo comprova as radicais mudanças pelas quais passam as culturas dominadas. Entretanto, pelo menos nos dias atuais, será mesmo o contato com a LE provocador da atribuição de superioridade as culturas dos detentores do poder? Ou será que a ideologia hegemônica instala-se, como conviç̧ão, mesmo naqueles que pouco ou nada sabem da lingua do colonizador? Não estaria a ideologia do dominador, no caso específico do Brasil, sendo veiculada principalmente através da língua portuguesa? Pessoas que tiveram pouco ou nenhum contato com o ensino formal de inglês nào seriam tào "colonizadas" quanto aquelas que aprenderam essa língua? Tudo indica que a palavra estrangera, palavra no sentido mais amplo do termo, isto é, a ideologia do hegemônico, está sendo veiculada também, e principalmente, através da língua nacional. Atualmente o conceito de colonização se mantém no sentido de "massificar " partir 
de certas matrizes poderosas de imagens, opinioes e esteréotipos" (Bosi, 1992:383).

Em recente pesquisa, Moita Lopes (1996), através de questionários, verificou que professores de lingua inglesa têm uma "atitude de colonizado", especialmente em relação aos norteamericanos, favorecendo a cultura americana em detrimento da nacional. Por exemplo, brasileiro é considerado pelos professores pescuuisados como preguiçoso. menos organizado, menos honesto, enquanto os povos de lingua inglesa seriam mais trabalhadores. raalistas, disciplinados etc. A língua inglesa é considerada maıs fácil e mais precisa do que a portuguesa. Suas conclusões o levam a sugerir mudanças nos cursos universitários de formação de professores, a exemplo da Tanzânia, que tem como objetivo o ensino de inglês enquanto língua instrumental de acesso ao conhecimento do mundo, preocupando-se especialmente em preservar sua identidade cultural.

Aparentemente, esse resultado vem confirmar que o ensino de L.F é o principal veículo da ideologia dos colonizadores. Entretanto, o "imenso papel ideológico" (Bakhtin, 1990:101) da palavra estrangeira não é exatamente um problema situado na materialidade da língua. mas nos seus discursos. Ao que parece, é a palavra estrangeira traduzida que vem circulando na nossa vida social. Um questionário semelhante ao de Moita Lopes (op.cit.), aplicado junto a pessoas que pouco ou nada sabem de inglês, certamente produz o mesmo resultado que esse pesquisador obteve entre os professores de inglês. Fizemos uma réplica de parte dele e aplicamos entre estudantes e profissionais diversos (doze pessoas ao todo) e obtivemos respostas semelhantes àquelas dadas pelos professores de LE. Não é preciso saber uma palavra de inglês para ter acesso aos valores, à cultura e à civilização americana, porque é o poder econômico que atua na política e na sociedade de un pais, formando opinião. A instituição escolar e o professor reproduzem a ideologia vigente e nela se respaldam. Entretanto, não se trata de um círculo fechado; a maioria das instituições educacionais e os professores que nelas atuam têm autonomia suficiente para abrir espaço nos seus programas, para abordagens que incluam reflexões e posicionamentos criticos a partir de uma concepção de linguagem e de ensino que possibilite atitudes transformadoras. 
A ligação entre imperialismo e a cultura está bem ilustrada no texto de Moita Lopes (op. cit.), em uma análise diacrônica da colonização portuguesa e do neocolonialismo americano: ambos apresentam atitude paternalista quanto a nossa pseudo-incapacidade de progredir sozinhos - enquanto os primeiros colonizadores procuravam conquistar os índios pela catequese religiosa e mantinham o acesso à cultura restrito às universidades de além-mar, atualmente é a indústria cultural uma das grandes responsáveis pela formação de opiniões tão glorificantes acerca do povo e do país mais rico. Segundo esse autor,

[...] as noções de cultura e poder são freqüentemente associadas. Controlar a cultura è controlar o poder, e quem detém a cultura é o imperialista. Transmitir cultura significa impor a ideologia da classe dominante, que vai, é óbvio, atender diretamente aos seus próprios interesses. E nesse século, é veiculo dessa ideologia a máquina da indústria cultural que envolve a tudo e a todos, principalmente pela penetração dos meios de comunicação (op.cit.:47 - grifo nosso).

São dois problemas relacionados à ideologia e à cultura que estão sendo focalizados neste capítulo: o que existe (reprodução) e o que pode existir (transformação). Se o momento atual constitui tempo escolhido pelo MEC para rever as práticas escolares e para retormulações curriculares e de programas de ensino pelas Secretarias de Educação estaduais, é também mais do que oportuna, antes de iniciar as mudanças, a criação de um espaço para reflexão, entre os professores, sobre o papel das línguas, das culturas, das ideologias e sobre o seu próprio papel nos contextos escolares, caso contrário esses professores estariam, mais uma vez, reproduzindo idéias ao invés de participar conscientemente das transformações.

Do ponto de vista da LE, a principal questão a ser considerada é un ensino de LE que não perca de vista os interesses da nossa cultura e da preservação de nossa identidade cultural. Não se justifica una aprovação cega a tudo que é inglês ou americano, mas no outro extremo também não há razão para repudiar completamente as outras culturas em nome da pureza de nossas raizes. Não resta dúvida de que, mesmo que o professor não seja o principal transmissor da visão colonizadora (ele também é colonizado), ele é, paradoxalmente, quem está mais bem colocado para começar a mudar essa situação, caso esteja preparado para essa tarefa. A pseudoneutralidade no tratamento das linguas - estrangeira e materna -, manifestada tipicamente por 
uma perspectiva decifratória, direcionada para a comunicação "eliciente"e para leitura informativa, escamoteia uma situação que deve ser aberta e freqüentemente discutida: a imposição cultural e ideológica tanto na dimensão nacional (por exemplo, a valorização de dialetos e de costumes em detrimento de outros) quanto na internacional (os estereótipos que nos diminuem em favor de outros povos).

A questão fundamental no ensino de L.E é o aprender a conviver com a diversidade: apreciar, discordar, respeitar. ver e entender. Não se justifica tentar apagar os elementos culturais das linguas como se eles contaminassem a nossa cultura. ou os assumir como se fossem ideais a ser alcançados. O pior é o que vem acontecendo: muitas pessoas estão atravessadas pela ideologia estrangeira e nem ao menos desconfiam disso. Lstar preparado para ver a diferença é também ter subsidios concretos para fortalecer nossa auto-estima e nossa identidade cultural. Esse trabalho de conscientização tem a instituição escolar como pedra fundamental. mas só uma pedagogia dialógica (fundada na interação social) pode realiza-lo. A convivência com outra cultura não implica necessariamente integrá-la a nossa; nào temos que ser biculturais para sermos bilíngües apesar das afirmações em contrário - nem engajarnos no famoso caldeirào cultural que McLuhan previu para o mundo só porque entramos em contato com as regras que regem o comportamento social de uma outra cultura ou porque conhecemos seus costumes. Ao contrário, conhecê-los e entendè-los nas suas relaçoes internas e externas é que vai permitir o questionamento e uma deliniçào clara sobre o papel e o lugar que as I.E ocupam na nossa socredade.

A sociedade brasileira reconhece várias culturas tais como a indigena, a negra, a popular, a erudita etc., contudo, aquela que a instituição escolar representa, coincide com os padróes da classe privilegrada; as restantes estão, em geral, bem delimitadas dentro de grupos minoritários e não constituem saber valorizado. Entretanto. é pela apreciação das diferentes formas de fazer cultura, tanto dentro das fronteras de uma nação quanto no âmbito mundial. combinada com uma reflexão acerca do contexto (histórico e imediato) e das relaçóes sociais, que se promoverá uma compreensão mais abrangente das diferenças e dos valores e, a partir desse referencial, a educação vem a oferecer um maior acesso à análise critica e à transformação. 
$\hat{E}$ através da linguagem que o conhecimento e a reflexão acerca da ciência, da cultura e do cotidiano são desenvolvidos. No entanto, aprender uma lingua não é somente reconhecer e usar modelos morfológicos, sintáticos e textuais pré-estabelecidos ou analisar sua organização enquanto sistema, mas é também saber que . unna ou várias culturas e ideologias circulam nos discursos, é saber aceitar. entender, recusar, controlar; analisar seu papel e sua função nos diferentes contextos histórico-sociais. É nessa linguagem - ação que modifica (Orlandi, 1987:25) - que a pedagogia das linguas encontra seu compromisso de educar para a cidadania e para a cmancipação. ${ }^{\text {s }}$

\section{REFER̂̂NCIAS BIBLIOGRÁFICAS}

BAKIITIN, Mikhail. Marismo e filosofia da linguagem. São Paulo : Ilucitec, 1990.

BL:NNETT, Milton. Beyond tolerance: intercultural communication in a multicultural society. TESOL Matters. U.S.A. : Tesol ed., April/May 1996.

BOSI, Alfredo. Dialética da colonizaçũo. 2. ed. São Paulo: Cia das l.etras, 1992.

BROWN. H. Principles of language learning and teaching. 3rd. ed. U.S.A.: Prentice Hall Regents, 1994.

JUCQUOIS, Guy. Leur enseigner leur langue. ITL Review of Applied Linguistics. Leuven : [s.n.], September, 1994.

KRAMSCH, Claire. Context and culture in language teaching. 2nd ed. Oxford: Oxford University Press, 1994.

MOITA LOPES. I uiz Paulo da. Oficina de lingüistica aplicada: A natureza social e educacional dos processos de aprendizagem de linguas. Campinas: Mercado de Letras, 1996.

Lste texto é parte da minha dissertaçào de mestrado denominada "Lingua materna e língua estrangeira: contribuições para uma proposta de interdisciplinaridade", defendida em 1996. 
ORLANDI, Eni. A linguagem e seu funcionamento: as formas do discurso. 2. ed. Campinas: Pontes, 1987.

PERUS, Françoise. Cultura, Ideologia, Formaciones Ideologicas y Practicas Discursivas. Discurso: Cadernos de Teoria y Analisis (5). [s.l. s.n.], Set./Dic. 1984.

SANTOS, Boaventura de Sousa. Pela Mão de Alice: O Social e o Politico na pós-modernidade. São Paulo: Cortez, 1995.

TOURRAINE, Alain. O que é a Democracia? Rio de Janeiro: Vozes, 1996.

ZIMA, Peter. Los mecanismos de la ideologia. Semiosis (11). [s.1. s.n.]. Jul./Dic. 1983.

\section{DOCUMENTOS}

Documento Curricular de Educação Geral para Ensino de $2^{\circ}$ Grau. Estado de Alagoas, Secretaria de Educação e Cultura, Equipe de Métodos, Currículos e Programas, 1982.

Relatório Preliminar SAEB (Sistema Nacional de Avaliação da Educação Básica) MEC/SEDIAE .Brasília, abril de 1996. 